\title{
Operational Fault Diagnosis in Industrial Hydraulic Systems Through Modeling the Internal Leakage of its Components
}

\author{
P. Athanasatos, D. Koulocheris, T. Costopoulos and K. Raptis \\ Department of Mechanical Engineering, \\ National Technical University of Athens, IroonPolytechneiou 9, Athens 15780, Greece
}

Received 2013-09-30, Revised 2013-10-05; Accepted 2013-11-07

\begin{abstract}
In this study, a model of a high pressure hydraulic system was developed using the bond graph method to investigate the effect of the internal leakage of its main components (pump, cylinder and 4/2 way valve) on the operational characteristics of the system under various loads. All the main aspects of the hydraulic circuit (like the internal leakages, the compressibility of the fluid, the hydraulic pressure drop, the inertia of moving masses and the friction of the spool) were taken into consideration. The results of this modeling were compared with the experimental data taken from the literature and from an actual test platform installed in the laboratory. Modeling and experimental data curves correlate very well in form, magnitude and response times for all the system's main parameters. This proves that the present method can be used to accurately model the response and operation of hydraulic systems and can thus be used for operational fault diagnosis in many cases, especially in simulating fault scenarios when the defective component is not obvious. This is very important in industrial production systems where unpredictable shutdowns of the hydraulic machinery have a considerable negative economic impact on cost.
\end{abstract}

Keywords: Hydraulic Systems, Modeling, Simulation, Fault Finding, Bond Graphs, Hydraulic Cylinder, Direction Control Valve

\section{INTRODUCTION}

\subsection{General Description}

The bond graph method is used to create a model of a high pressure hydraulic system in order to simulate various degrees of internal leakage in its 4/2 way direction control valve and hydraulic cylinder under different loads. For the modeling, all the main aspects of the hydraulic system were taken into consideration: The internal leakage in the pump the cylinder and the $4 / 2$ way valve, the leakage flow caused both due to pressure gradient (Hagen-Poiseuille flow) and due to the relative motion of the piston to the cylinder body (Couette flow), the compressibility of the hydraulic fluid, the pressure drop due to hydraulic losses, the inertia of moving masses in the cylinder and the friction in the hydraulic cylinder spool. The results of modeling were compared against the experimental data from the literature and from an actual hydraulic test platform installed in the laboratory. The goal is to investigate whether bond graph modeling can be used as a tool for proactive fault finding in high pressure hydraulic systems, by accurately simulating various operating states of the system.

\subsection{Fault Detection in Hydraulic Systems, the Bond Graph Method and Related Work}

A useful insight into the scope, operation and ccomponents of high pressure hydraulic systems can be found in the textbooks of A useful insight into the scope, operation and ccomponents of high pressure hydraulic IroonPolytechneiou 9, Athens 15780, Greece 
systems can be found in the textbooks of Meritt (1991); Costopoulos (2009) and Rabie (2009), while the subject of condition monitoring techniques for industrial high pressure hydraulic systems is examined by Skarmea (2003). As far as the modeling of hydraulic systems is concerned, an in depth research has been conducted by Kaliafetis and Costopoulos (1995) on the modeling of axial piston variable displacement pumps, where as Noorbehesht and Ghaseminejad (2013) performed numerical simulation using a computational fluid dynamics method.

The Bond Graph method, albeit comparatively new, is rather popular for modeling physical systems, but its applications in high pressure hydraulic systems remain somewhat limited. A comparison of the Bond Graph method with object oriented modeling is done by Borutzky (2002), where it was found that both methods can be equally reliable, if they are used in appropriate applications and effectively implemented. The basics of bond graph based control and substructuring are analyzed by Gawthorp et al. (2009), while Krishnaswamy and Li (2006) used the Bond Graph method in the passive teleoperation of a hydraulic backhoe. Additional work in the field of bond graph modeling of nonlinear hydro-mechanical systems has been conducted by Margolis and Shim (2005), while Li and Ngwempo (2005) have used bond graph modeling in electro-hydraulic valves. The dynamic response of a high pressure hydraulic system using bond graphs is examined by Barnard and Dransfield (1977), while Dransfield (1981) dealt with the application of bond graphs to hydraulic systems. The concept of using bond graphs for the study of faults and failures in hydraulic systems has been investigated by Athanasatos and Costopoulos (2011) where bond graph modeling is used to predict the response of a hydraulic system with irregular motion of its spool. In the area of maintenance, quality and reliability of industrial systems several works have been published: Zotos and Costopoulos (2012) examined precision maintenance whereas Siam et al. (2012) examined the total quality management, Valarmathi and Chilambuchelvan (2012) investigated a wind turbine through a power quality analysis and Zotos and Costopoulos (2008) give specific orders for the increase of numerical stability and accuracy.

\subsection{The Hydraulic System to be Modeled}

The line drawing of the hydraulic system used as the test platform can be seen in Fig. 1. The main components and measuring instruments of the hydraulic system are explained in Table 1.
Table 1. Components of the hydraulic system

\begin{tabular}{ll}
\hline Number/ & \\
symbol & Component \\
\hline 1 & Vane Pump \\
2 & Electric Motor \\
3 & Return Line Oil Filter \\
4 & Main Relief Valve \\
$5,18,19$ & Pressure Gauges \\
6,9 & Flow Control Valves \\
7 & $4 / 2$ Way Valve \\
8 & Flow Control Valve \\
10 & $4 / 2$ Way Valve \\
11 & $4 / 2$ Way Direction Control Valve \\
12,17 & Shutoff Switches \\
13,16 & Check Valves \\
20 & Thermometer \\
24,25 & Terminal Switch \\
26 & Hydraulic Cylinder \\
14,15 & Manual Load Valves \\
A & Pressure Transducer \\
B & Flowmeter \\
C & Flowmeter \\
D & Pressure Transducer \\
E & Linear Encoder \\
F & Two-stage electrically operated load control valve \\
G & Pressure Transducer \\
H & Flow Control Valve for internal leakage simulation \\
I & Flow Control Valve for internal leakage simulation \\
J & Flowmeter \\
K & Pressure Transducer \\
L & Check valve \\
\hline
\end{tabular}

The system can be used to simulate a variety of operating conditions. Due to the focus on the internal leakage of the hydraulic cylinder (26) and the 4/2 way direction control valve (11) additional flow control valves have been installed in order to simulate an increase of the internal leakage of these two components. The internal leakage on the hydraulic cylinder is simulated via throttle valve $(\mathrm{H})$ which, when open, allows some amount of flow to bypass the cylinder. Similarly, the internal leakage in the $4 / 2$ way valve is simulated via throttle valve (I) which, when open, allows flow directly from port " $\mathrm{P}$ " of the valve to port " $\mathrm{T}$ ".

\section{MODELING PROCEDURE FOR THE HYDRAULIC SYSTEM}

\subsection{Symbol Nomenclature}

The main symbols that appear in the bond graph components and the resulting equations are the following: 


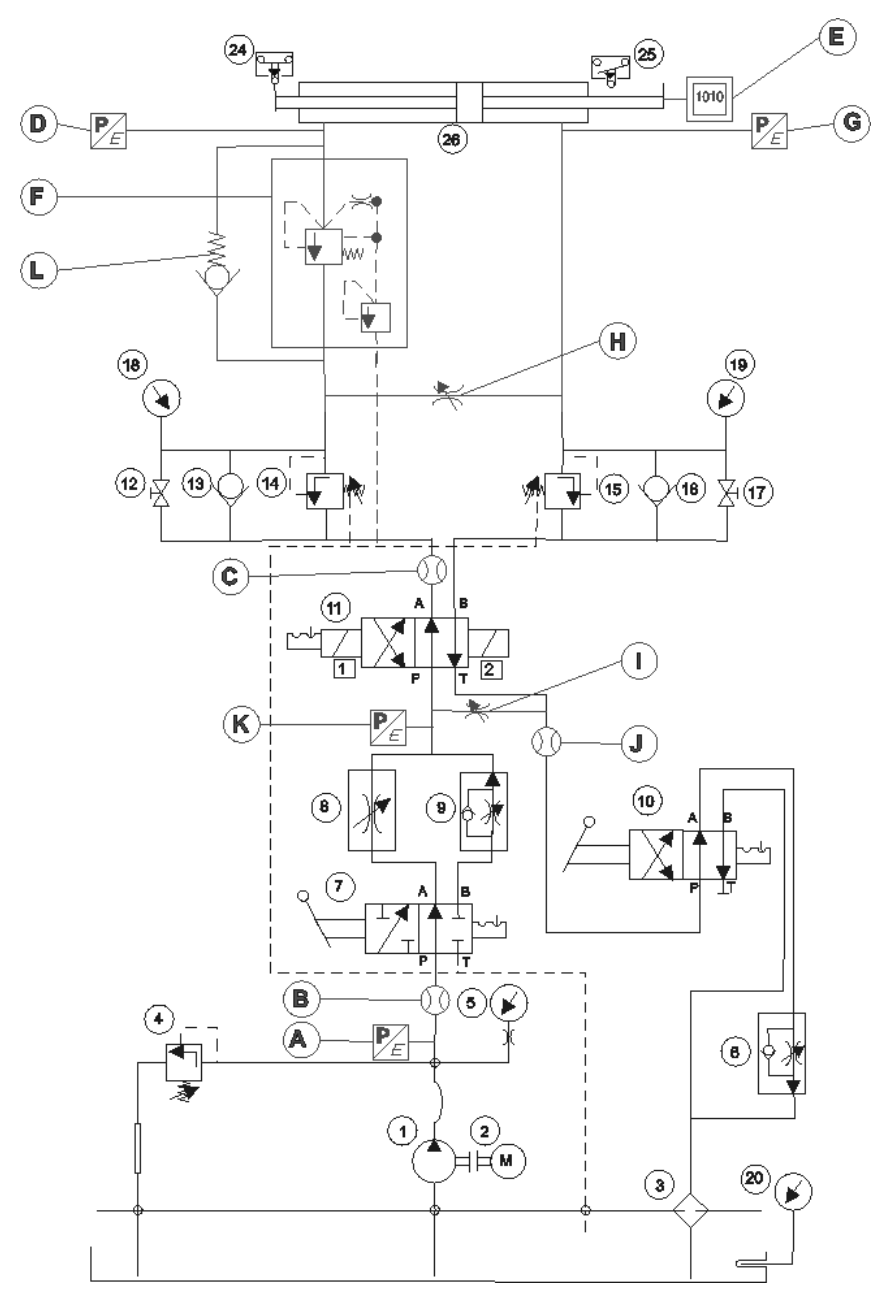

Fig. 1. Line diagram of the hydraulic system to be modeled

\section{Symbols}

$\mathrm{A}=$ Hydraulic cylinder piston surface

$\mathrm{c}=$ Radial clearance

$\mathrm{C}=$ Hydraulic capacitance

$\mathrm{D}=$ Piston diameter

$\mathrm{F}=$ Force

$\mathrm{K}=$ Flow coefficient

$\mathrm{L}=$ Length of hydraulic cylinder piston

$\mu=$ Absolute fluid viscosity

$\mathrm{m}=$ mass

$\mathrm{N}=$ Valve spool displacement to maximum valve spool displacement ratio

$\mathrm{P}=$ Pressure

$\mathrm{PR}=$ Pressure drop

$\mathrm{Q}=$ Flow rate

$\mathrm{R}=$ Hydraulic resistance
$\mathrm{SF}=$ Equivalent
$\mathrm{t}=$ Time elapsed
$\mathrm{T}=$ Torque on electric motor shaft
$\mathrm{V}=$ Geometric displacement per radian rotation of the pump
$\mathrm{W}=$ Maximum valve spool displacement
$\mathrm{x}=$ Hydraulic cylinder piston displacement
$\dot{\mathrm{x}}=$ Hydraulic cylinder piston velocity
$\mathrm{X}_{\mathrm{i}}=$ Valve spool displacement $(\mathrm{Xi}>0$ when flow paths $\mathrm{P}->\mathrm{A}$ and $\mathrm{B}->\mathrm{T}$ are enabled)
$\omega=$ Angular velocity of electric motor and pump shaft

\section{Subscripts}

1 = hydraulic cylinder right chamber

$2=$ hydraulic cylinder left chamber

$\mathrm{A}=$ valve "A" port 


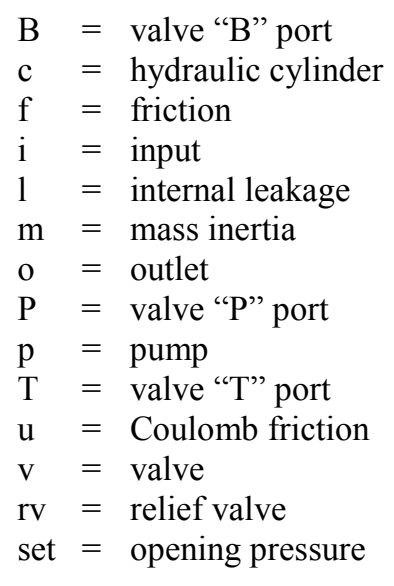

\subsection{Modeling the System's Main Components}

To simplify the modeling procedure, each main component of the system was modeled separately. Due to the focus on the hydraulic cylinder and the direction control valve, detailed models are developed for these two components. In order to avoid an overly complex model of the hydraulic system, simpler models were used for the rest of the components, but without any sacrifice in terms of modeling accuracy. The components of the hydraulic system were modeled as following.

\subsubsection{Electric Motor, Pump and Main Relief Valve}

The electric motor is modeled as a constant flow source (angular velocity) mated to a transformer (pump), resulting in constant flow rate $\mathrm{Q}_{\mathrm{p}}$. The pressure at the pump outlet is modeled as a " 0 " junction, on which the following are considered: The compressibility of the hydraulic fluid at the pump outlet $\left(\mathrm{C}_{\mathrm{p}}\right)$, the pump internal leakage flow path $\left(\mathrm{R}_{\mathrm{lp}}\right)$ and the flow path of fluid when the main relief valve of the system opens $\left(R_{\mathrm{rv}}\right)$.

\subsubsection{Section from Pump Outlet to $4 / 2$ Way Valve Inlet}

The pressure drop from the pump outlet until the $4 / 2$ way valve inlet is modeled as a negative effort (pressure) source mated to a common flow " 1 " junction.

\subsubsection{4/2 Way Direction Control Valve}

The 4/2 way direction control valve is modeled as a series of fluid flow paths, each with its own flow resistance. The flow resistance is a function of the valve spool position, meaning that the flow resistance varies from infinite (when a particular passage is blocked for a certain operating position of the valve) to a minimum value, when the spool is set in place. Also, the internal leakage of the $4 / 2$ way valve is modeled as a fluid flow path from port "P" to port " $T$ " of the valve.

\subsubsection{Section from Valve Outlet to Tank}

The pressure drop from the pump outlet until the $4 / 2$ way valve inlet is modeled as a negative effort (pressure) source.

\subsubsection{Hydraulic Cylinder and Equivalent Load}

The hydraulic cylinder is essentially modeled as two transformers, one converting pressure and flow rate to linear motion and force (which represents the chamber connected to the pressure line) and another converting linear motion and force to pressure and flow rate (to model the connection of the chamber to the return line). For the modeling of the hydraulic cylinder, the internal leakage past the piston was included, taking into consideration both the leakage flow caused by the pressure gradient (Hagen-Poiseuille flow) as well as the leakage flow caused by the relative motion of the piston to the cylinder body (Couette flow). The compressibility of the fluid in the two cylinder chambers as well as the effects of friction (both Coulomb and viscous) and inertia due to the moving mass of the cylinder piston and rods were also included in the modeling. Finally, the equivalent load is simulated as a negative effort (force) source, exerted at the cylinder rod tip. Due to the reversal of the cylinder piston motion and the subsequent reversal in the flow of power, two different bond graphs for the cylinder and load were used: One shown in Fig. 2, for the modeling of motion to the left and another shown in Fig. 3, for modeling the power flow during motion to the right. More details of this modeling procedure may be found in Athanasatos and Costopoulos (2011).

\subsubsection{Check Valve "L"}

Check valve " $L$ " is used to bypass the electrically operated control valve used to simulate the load in the hydraulic system. The pressure drop it causes is modeled as a negative effort source during the return phase, whereas it is zero during the work phase (since the oil flows through the load control valve).

\subsection{Hydraulic System Model Bond Graph Model Equation Layout}

By combining the bond graph models for the hydraulic system's components, we have created the bond graph model of the entire hydraulic system, as in Athanasatos and Costopoulos (2011).

The equations for the components of the bond graph are the following. 


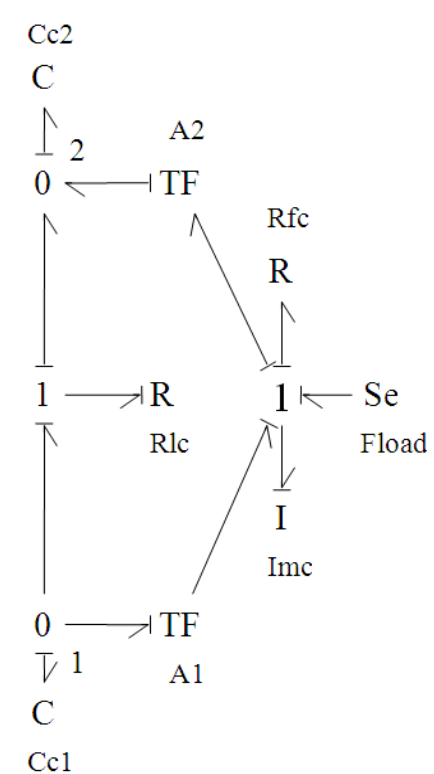

Fig. 2. Bond graph model of hydraulic cylinder and equivalent load during the piston motion the left

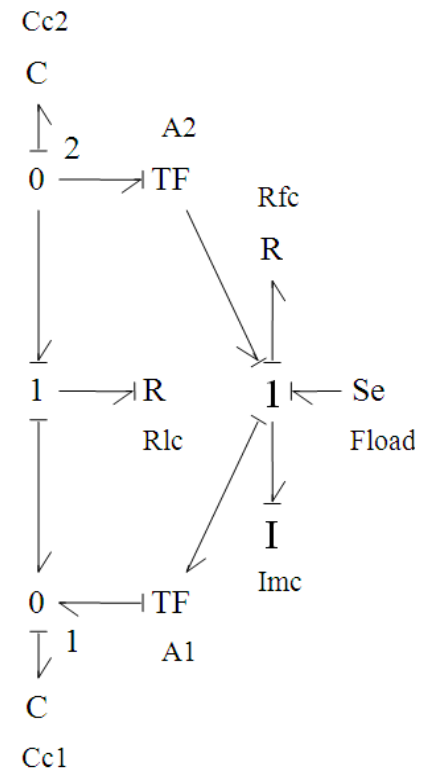

Fig. 3. Bond graph model of hydraulic cylinder and equivalent load during the motion of the piston to the right (return phase)

2.4. Electric Motor, Pump and Main Relief Valve Equation (1 to7):

Swm: $\omega=$ const,

(1)

$$
\begin{aligned}
& T_{\mathrm{p}}: \mathrm{Q}_{\mathrm{p}}=\omega \cdot \mathrm{V}_{\mathrm{p}} \\
& \mathrm{T}_{\mathrm{p}}=\frac{1}{\mathrm{~V}_{\mathrm{p}}} \cdot \mathrm{P}_{\mathrm{p}} \\
& \mathrm{C}_{\mathrm{p}}: \mathrm{P}_{\mathrm{p}}=\mathrm{P}_{\mathrm{p}}(0)+\frac{1}{\mathrm{C}_{\mathrm{p}}} \cdot \int \Delta \mathrm{Q}_{\mathrm{p}} \cdot \mathrm{dt} \\
& \mathrm{R}_{\mathrm{lp}}: \mathrm{Q}_{\mathrm{lp}}=\frac{\mathrm{P}_{\mathrm{p}}}{\mathrm{R}_{\mathrm{lp}}} \\
& \mathrm{R}_{\mathrm{rv}}: \mathrm{Q}_{\mathrm{rv}}=0 \text { if } \mathrm{P}_{\mathrm{p}}<\mathrm{P}_{\text {set }} \\
& \mathrm{Q}_{\mathrm{rv}}=\frac{\left(\mathrm{P}_{\mathrm{p}}-\mathrm{P}_{\text {set }}\right)}{\mathrm{R}_{\mathrm{rv}}} \text { if } \mathrm{P}_{\mathrm{p}} \geq \mathrm{P}_{\text {set }} \\
& 0-\text { junction : } \Delta \mathrm{Q}_{\mathrm{p}}=\mathrm{Q}_{\text {ip }}-\mathrm{Q}_{\mathrm{lp}}-\mathrm{Q}_{\mathrm{rv}}-\mathrm{Q}_{\mathrm{op}}
\end{aligned}
$$

2.5. Section from Pump Outlet to $4 / 2$ Way Valve Inlet Equation (8 and 9):

$$
\begin{aligned}
& \mathrm{R}_{\mathrm{pv}}: \quad \mathrm{PR}_{\mathrm{pv}}=-\Delta \mathrm{P}_{\mathrm{pv}}=\text { const } \\
& 1-\text { junction } \Delta \mathrm{PR}_{\mathrm{pv}}=\mathrm{P}_{\mathrm{i}}-\mathrm{P}_{\mathrm{o}}
\end{aligned}
$$

\subsection{4/2 Way Direction Control Valve}

0-junctions Equation (10 to 13 ):

$$
\begin{aligned}
& \mathrm{Q}_{\mathrm{P}}=\mathrm{Q}_{\mathrm{PA}}+\mathrm{Q}_{\mathrm{PB}}+\mathrm{Q}_{\mathrm{lv}} \\
& \mathrm{Q}_{\mathrm{T}}=\mathrm{Q}_{\mathrm{AT}}+\mathrm{Q}_{\mathrm{BT}}+\mathrm{Q}_{\mathrm{lv}} \\
& \mathrm{Q}_{\mathrm{A}}=\mathrm{Q}_{\mathrm{PA}}-\mathrm{Q}_{\mathrm{AT}} \\
& \mathrm{Q}_{\mathrm{B}}=\mathrm{Q}_{\mathrm{PB}}-\mathrm{Q}_{\mathrm{BT}}
\end{aligned}
$$

1-junctions Equation (14 to 23):

$\Delta \mathrm{P}_{\mathrm{PA}}=\mathrm{P}_{\mathrm{P}}-\mathrm{P}_{\mathrm{A}}$

$\Delta \mathrm{P}_{\mathrm{PB}}=\mathrm{P}_{\mathrm{P}}-\mathrm{P}_{\mathrm{B}}$

$\Delta \mathrm{P}_{\mathrm{AT}}=\mathrm{P}_{\mathrm{A}}-\mathrm{P}_{\mathrm{T}}$

$\Delta \mathrm{P}_{\mathrm{BT}}=\mathrm{P}_{\mathrm{B}}-\mathrm{P}_{\mathrm{T}}$ 


$$
\begin{array}{ll}
\Delta \mathrm{P}_{\mathrm{PT}}=\mathrm{P}_{\mathrm{P}}-\mathrm{P}_{\mathrm{T}} & \\
\mathrm{R}_{\mathrm{PA}}: \mathrm{Q}_{\mathrm{PA}}=0 & \text { if } \mathrm{N}=0 \\
\mathrm{Q}_{\mathrm{PA}}=\mathrm{K}_{\mathrm{PA}} \cdot|\mathrm{N}| \cdot \sqrt{\Delta \mathrm{P}_{\mathrm{PA}}} & \text { if }-1 \leq \mathrm{N}<0 \\
\mathrm{Q}_{\mathrm{PA}}=0 & \text { if } \mathrm{N}>0 \\
\mathrm{R}_{\mathrm{PB}}: \mathrm{Q}_{\mathrm{PB}}=0 & \text { if } \mathrm{N}=0 \\
\mathrm{Q}_{\mathrm{PB}}=\mathrm{K}_{\mathrm{PB}} \cdot \mathrm{N} \cdot \sqrt{\Delta \mathrm{P}_{\mathrm{PB}}} & \text { if } 0<\mathrm{N} \leq 1 \\
\mathrm{Q}_{\mathrm{PB}}=0 & \text { if }-1 \leq \mathrm{N}<0 \\
\mathrm{R}_{\mathrm{AT}}: \mathrm{Q}_{\mathrm{AT}}=0 & \text { if } \mathrm{N}=0 \\
\mathrm{Q}_{\mathrm{AT}}=\mathrm{K}_{\mathrm{AT}} \cdot \mathrm{N} \cdot \sqrt{\Delta \mathrm{P}_{\mathrm{AT}}} & \text { if } 0<\mathrm{N} \leq 1 \\
\mathrm{Q}_{\mathrm{AT}}=0 & \text { if }-1 \leq \mathrm{N}=0 \\
\mathrm{R}_{\mathrm{BT}}: \mathrm{Q}_{\mathrm{BT}}=0 & \text { if } 0<\mathrm{N} \leq 1 \\
\mathrm{Q}_{\mathrm{BT}}=0 & \text { if }-1 \leq \mathrm{N}<0 \\
\mathrm{Q}_{\mathrm{BT}}=\mathrm{K}_{\mathrm{BT}} \cdot|\mathrm{N}| \cdot \sqrt{\Delta \mathrm{P}_{\mathrm{BT}}} & \\
& \\
\mathrm{R}_{\mathrm{lv}}: \mathrm{Q}_{\mathrm{lv}}=2 \cdot \frac{\pi \cdot \mathrm{D}_{\mathrm{v}} \cdot \mathrm{c}_{\mathrm{v}}{ }^{3}}{12 \cdot \mu \cdot\left|\mathrm{X}_{\mathrm{i}}\right|} \cdot \Delta \mathrm{P} \\
\text { with }-\mathrm{W}_{\leq \mathrm{X}} \leq \mathrm{W} &
\end{array}
$$

\subsection{Section from Valve Outlet to Tank Equation (24):}

$\mathrm{S}_{\mathrm{e}}: \mathrm{PR}_{\mathrm{vt}}=-\Delta \mathrm{P}_{\mathrm{vt}}=$ const

\subsection{Hydraulic Cylinder and Equivalent Load}

A) Piston movement to the left

0 -junctions Equation (25 and 26):

$$
\begin{aligned}
& \Delta \mathrm{Q}_{1}=\mathrm{Q}_{1}-\mathrm{A}_{1} \cdot \dot{\mathrm{x}}-\mathrm{Q}_{\mathrm{lc}} \\
& \Delta \mathrm{Q}_{2}=\mathrm{A}_{2} \cdot \dot{\mathrm{x}}+\mathrm{Q}_{\mathrm{lc}}-\mathrm{Q}_{2}
\end{aligned}
$$

1-junctions Equation (27 and 28):

$$
\begin{aligned}
& \Delta \mathrm{P}_{12}=\mathrm{P}_{1}-\mathrm{P}_{2} \\
& \Delta \mathrm{F}=\mathrm{P}_{1} \cdot \mathrm{A}_{1}-\mathrm{P}_{2} \cdot \mathrm{A}_{2}-\mathrm{F}_{\mathrm{fc}}-\mathrm{F}_{\mathrm{mc}}+\mathrm{SF}_{\text {load }}
\end{aligned}
$$

$$
\mathrm{A}_{1} \text { transformer Equation (29 and 30): }
$$

$$
\begin{aligned}
& \mathrm{F}=\mathrm{P}_{1} \cdot \mathrm{A}_{1} \\
& \dot{\mathrm{x}}=\frac{\mathrm{Q}_{1}}{\mathrm{~A}_{1}}
\end{aligned}
$$

$\mathrm{A}_{2}$ transformer Equation (31 and 32):

$\mathrm{Q}_{2}=\mathrm{A}_{2} \cdot \dot{\mathrm{x}}$

$\mathrm{P}_{2}=\frac{\mathrm{F}}{\mathrm{A}_{2}}$

$\mathrm{C}_{\mathrm{c} 1}$ capacitance Equation (33):

$\mathrm{P}_{1}=\mathrm{P}_{1}(0)+\frac{1}{\mathrm{C}_{\mathrm{c} 1}} \cdot \int \Delta \mathrm{Q}_{1} \cdot \mathrm{dt}$

$\mathrm{C}_{\mathrm{c} 2}$ capacitance Equation (34):

$\mathrm{P}_{2}=\mathrm{P}_{2}(0)+\frac{1}{\mathrm{C}_{\mathrm{c} 2}} \cdot \int \Delta \mathrm{Q}_{2} \cdot \mathrm{dt}$

$\mathrm{I}_{\mathrm{mc}}$ inertial phenomenon Equation (35):

$\dot{\mathrm{x}}=\dot{\mathrm{x}}(0)+\frac{1}{\mathrm{~m}_{\mathrm{c}}} \cdot \int \mathrm{F}_{\mathrm{mc}} \cdot \mathrm{dt}$

$\mathrm{R}_{\mathrm{lc}}$ resistance Equation (36):

$\mathrm{Q}_{\mathrm{lc}}=\frac{\pi \cdot \mathrm{D}_{\mathrm{c}} \cdot \mathrm{c}^{3}}{12 \cdot \mu \cdot \mathrm{L}} \cdot \Delta \mathrm{P}_{12}+\frac{1}{2} \cdot \pi \cdot \dot{\mathrm{x}} \cdot \mathrm{D} \cdot \mathrm{c}$

$\mathrm{R}_{\mathrm{fc}}$ resistance Equation (37):

$\mathrm{F}_{\mathrm{fc}}=\operatorname{sgn}(\dot{\mathrm{x}}) \cdot \mathrm{F}_{\mathrm{u}}+\mathrm{K}_{\mathrm{f}} \cdot \dot{\mathrm{x}}$

$\mathrm{SeF}_{\text {load }}$ Equation (38):

$\mathrm{SeF}_{\text {load }}=\mathrm{F}_{\text {load }}=$ const

B) Piston movement to the right

0 -junctions Equation (39 and 40):

$\Delta \mathrm{Q}_{2}=\mathrm{Q}_{2}-\mathrm{A}_{2} \cdot \dot{\mathrm{x}}-\mathrm{Q}_{\mathrm{lc}}$

$\Delta \mathrm{Q}_{1}=\mathrm{A}_{1} \cdot \dot{\mathrm{x}}+\mathrm{Q}_{\mathrm{lc}}-\mathrm{Q}_{1}$ 
1-junctions Equation (41 and 42):

$\Delta \mathrm{P}_{21}=\mathrm{P}_{2}-\mathrm{P}_{1}$

$\Delta \mathrm{F}=\mathrm{P}_{2} \cdot \mathrm{A}_{2}-\mathrm{P}_{1} \cdot \mathrm{A}_{1}-\mathrm{F}_{\mathrm{fc}}-\mathrm{F}_{\mathrm{mc}}+\mathrm{SF}_{\text {load }}$

$\mathrm{A}_{2}$ transformer Equation (43 and 44):

$\dot{\mathrm{x}}=\frac{\mathrm{Q}_{2}}{\mathrm{~A}_{2}}$

$\mathrm{F}=\mathrm{P}_{2} \cdot \mathrm{A}_{2}$

$\mathrm{A}_{1}$ transformer Equation (45 and 46):

$\mathrm{P}_{1}=\frac{\mathrm{F}}{\mathrm{A}_{1}}$

$\mathrm{Q}_{1}=\dot{\mathrm{x}} \cdot \mathrm{A}_{1}$

$\mathrm{C}_{\mathrm{c} 1}$ capacitance Equation (47):

$\mathrm{P}_{1}=\mathrm{P}_{1}(0)+\frac{1}{\mathrm{C}_{\mathrm{a} 1}} \cdot \int \Delta \mathrm{Q}_{1} \cdot \mathrm{dt}$

$\mathrm{C}_{\mathrm{c} 2}$ capacitance Equation (48):

$\mathrm{P}_{2}=\mathrm{P}_{2}(0)+\frac{1}{\mathrm{C}_{\mathrm{a} 2}} \cdot \int \Delta \mathrm{Q}_{2} \cdot \mathrm{dt}$

$\mathrm{I}_{\mathrm{mc}}$ inertial phenomenon Equation (49):

$\dot{\mathrm{x}}=\dot{\mathrm{x}}(0)+\frac{1}{\mathrm{~m}_{\mathrm{c}}} \cdot \int \mathrm{F}_{\mathrm{mc}} \cdot \mathrm{dt}$

$\mathrm{R}_{\mathrm{lc}}$ resistance Equation (50):

$\mathrm{Q}_{\mathrm{lc}}=\frac{\pi \cdot \mathrm{D} \cdot \mathrm{c}_{\mathrm{c}}{ }^{3}}{12 \cdot \mu \cdot \mathrm{L}} \cdot \Delta \mathrm{P}_{21}+\frac{1}{2} \cdot \pi \cdot|\dot{\mathrm{x}}| \cdot \mathrm{D} \cdot \mathrm{c}$

$\mathrm{R}_{\mathrm{fc}}$ resistance Equation (51):

$\mathrm{F}_{\mathrm{fc}}=\operatorname{sgn}(\dot{\mathrm{x}}) \cdot \mathrm{F}_{\mathrm{u}}+\mathrm{K}_{\mathrm{f}} \cdot \dot{\mathrm{x}}$

$\mathrm{SeF}_{\text {load }}$ Equation (52):

$\mathrm{SeF}_{\text {load }}=\mathrm{F}_{\text {load }}=0$

\subsection{Check Valve «L»}

1-junction Equation (53):

$\Delta \mathrm{P}_{\mathrm{Rcv}}=\mathrm{P}_{\mathrm{i}}-\mathrm{P}_{\mathrm{o}}$

SeRcv Equation (54):

$\begin{array}{ll}\mathrm{PR}_{\mathrm{cv}}=-\Delta \mathrm{P}_{\mathrm{Rcv}}=\text { const } & \text { if } \mathrm{Q}_{\mathrm{PA}}>0 \\ \mathrm{PR}_{\mathrm{cv}}=0 & \text { if } \mathrm{Q}_{\mathrm{PA}} \leq 0\end{array}$

\subsection{Constants and Initial Conditions Definition}

Based on manufacturer data and measurements performed, the following constants and initial conditions were determined:

$\omega=1600 \mathrm{rpm}=167.55 \mathrm{rad} / \mathrm{s}$

$\mathrm{V}_{\mathrm{p}}=1.31 \mathrm{e}-5 \mathrm{~m}^{3} / \mathrm{rev}=\frac{1.375 \mathrm{e}-5}{2 \pi} \mathrm{m}^{3} / \mathrm{rad}$

$\mathrm{C}_{\mathrm{p}}=4.48 \mathrm{e}^{-12} \frac{\mathrm{m}^{3}}{\mathrm{~Pa}}$

$Q_{p}=\omega \cdot V_{p}=167.55 \cdot \frac{1.375 \mathrm{e}^{-5}}{2 \pi}=3.67 \mathrm{e}^{-4} \mathrm{~m}^{3} / \mathrm{s}$

$\mathrm{R}_{\mathrm{lp}}=6 \mathrm{e}-12 \frac{\mathrm{m}^{3}}{\mathrm{~s} \cdot \mathrm{Pa}}$

$\mathrm{P}_{\text {set }}=7.0 \mathrm{e} 6 \mathrm{~Pa}$

$\mathrm{R}_{\mathrm{rv}}=2.5 \mathrm{e}-9 \frac{\mathrm{m}^{3}}{\mathrm{~s} \cdot \mathrm{Pa}}$

$\mathrm{PR}_{\mathrm{pv}}=\Delta \mathrm{P}_{\mathrm{pv}}=-9.537 \mathrm{e} 4 \mathrm{~Pa}$.

$\mathrm{K}_{\mathrm{PA}}=\mathrm{K}_{\mathrm{PB}}=\mathrm{K}_{\mathrm{AT}}=\mathrm{K}_{\mathrm{BT}}=5.185 \mathrm{e}-7 \frac{\mathrm{m}^{3}}{\mathrm{~Pa}^{1 / 2} \cdot \mathrm{s}}$

$\mathrm{W}=0.02 \mathrm{~m}$

$\mathrm{D}_{\mathrm{v}}=23.5 \mathrm{~mm}$

$\mathrm{L}_{\mathrm{v}}=5 \mathrm{~mm}$

$\mu=0.0261 \mathrm{Ns} / \mathrm{m}^{2}$

$\mathrm{c}_{\mathrm{v}}=34 \mu \mathrm{m}$

$\mathrm{A}_{1}=\mathrm{A}_{2}=0.0021 \mathrm{~m}^{2}$

$\mathrm{C}_{\mathrm{cl}}=\frac{5.30 \cdot \mathrm{e}-4+2.1 \cdot \mathrm{e}-3 \cdot \mathrm{x}}{1.5 \cdot \mathrm{e} 9}\left(\frac{\mathrm{m}^{3}}{\mathrm{~Pa}}\right)$

$\mathrm{C}_{\mathrm{c} 2}=\frac{5.85 \cdot \mathrm{e}-4+2.1 \cdot \mathrm{e}-3 \cdot(0.5-\mathrm{x})}{1.5 \cdot \mathrm{e} 9}\left(\frac{\mathrm{m}^{3}}{\mathrm{~Pa}}\right)$

$\mathrm{D}_{\mathrm{c}}=60 \mathrm{~mm}$

$\mathrm{L}_{\mathrm{c}}=30 \mathrm{~mm}$

$\mathrm{c}_{\mathrm{c}}=83 \mu \mathrm{m}$ 


$$
\begin{aligned}
& \mathrm{F}_{\mathrm{u}}=163.2 \mathrm{~N} \\
& \mathrm{~K}_{\mathrm{f}}=1.49 \mathrm{e}^{3} \mathrm{~N} \cdot \mathrm{s} / \mathrm{m} \\
& \mathrm{m}_{\mathrm{c}}=7.32 \mathrm{~kg} \\
& \Delta \mathrm{PR}_{\mathrm{cv}}=0.1 \mathrm{e} 6 \mathrm{~Pa} \\
& \mathrm{PR}_{\mathrm{vt}}=-1.46 \mathrm{e} 5 \mathrm{~Pa} \\
& \mathrm{P}_{1}(0)=\mathrm{P}_{2}(0)=0 \mathrm{~Pa} \\
& \mathrm{x}(0)=0 \mathrm{~m} \\
& \dot{\mathrm{x}}(0)=\mathrm{v}(0)=0 \mathrm{~m} / \mathrm{s}
\end{aligned}
$$

\section{EXPERIMENTAL VALIDATION OF MODEL RESULTS}

\subsection{Comparison of Model and Actual System during Normal Operation}

To test the accuracy of the bond graph model, the results of the model were compared to the data of a test run performed with the actual hydraulic system.

For the test, load control valve "F" was adjusted as to create a backpressure of 10 bar (equivalent with a constant load of $2.1 \mathrm{kN}$ ) and flow control valves " $\mathrm{H}$ " and "I" were completely shut off. The results of the model run compared to the data from the actual system are shown in Fig. 4-7.

As seen in Fig. 4, the motion of the rod lasts $6.8 \mathrm{sec}$, with the working phase lasting $3.5 \mathrm{sec}$ and the return phase lasting $3.3 \mathrm{sec}$ and these values are accurately predicted by the model as well.
In Fig. 5 we see the velocity graph of the hydraulic cylinder rod. The average rod velocity in the working phase is $0.158 \mathrm{~m} / \mathrm{s}$ and in the return phase is $0.163 \mathrm{~m} / \mathrm{s}$.

The internal leakage flow rate through the hydraulic cylinder is shown in Fig. 6. The average internal leakage on the hydraulic cylinder is $1.8 \mathrm{e}-5 \mathrm{~m}^{3} / \mathrm{s}$, a value which also accurately predicted by the model.

Finally, in Fig. 7 we see the internal leakage through the $4 / 2$ way valve during the work phase. The average internal leakage flow rate is $8.5 \mathrm{e}-6 \mathrm{~m}^{3} / \mathrm{s}$, a value which is also predicted by the model. From the comparison of the actual with the model data it is evident that there is a very good correlation in the shape and maximum/minimum values of the curves in all of the main operating parameters of the hydraulic system.

\subsection{Results for Internal Leakage of the Hydraulic Cylinder}

The results of the model were compared to the ones of the actual system in terms of the equivalent internal leakage flow rate in the working phase and the ratio of the average speed in the working phase to the average speed in the return phase. The results are shown in the following Fig. 8 and 9, where there is a very good correlation between the experimental and the measurement data and the regression curves for both the experimental (continuous line) and the model data (dashed line) have the form of a 3rd degree polynomial equation.

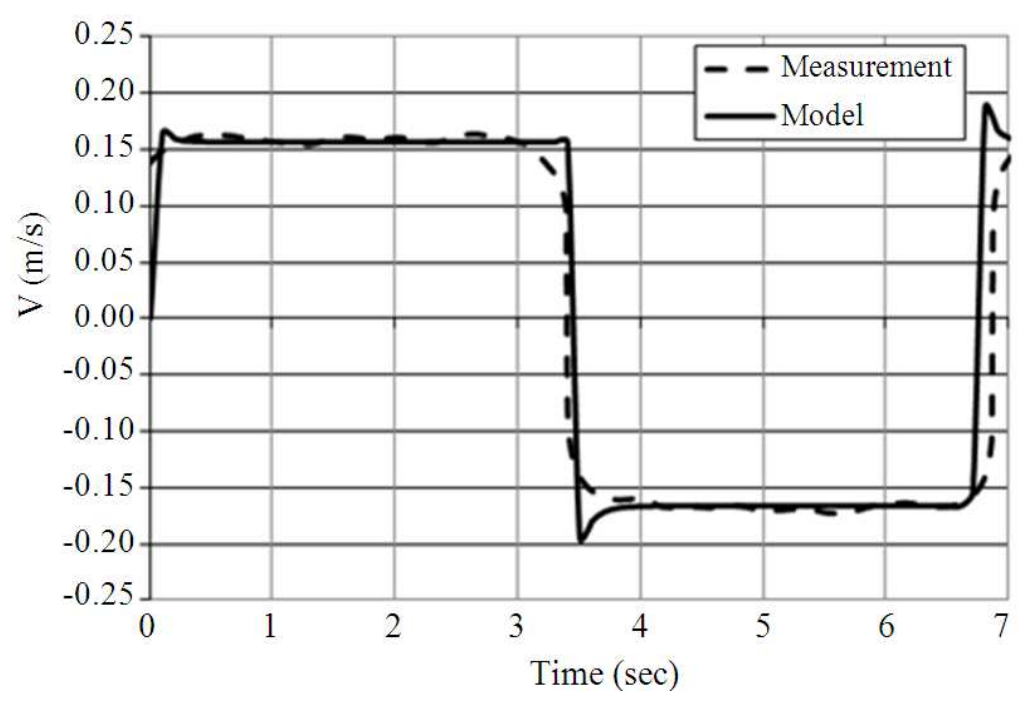

Fig. 4. Hydraulic cylinder rod displacement 
P. Athanasatos et al. / American Journal of Applied Sciences 10 (12): 1648-1659, 2013

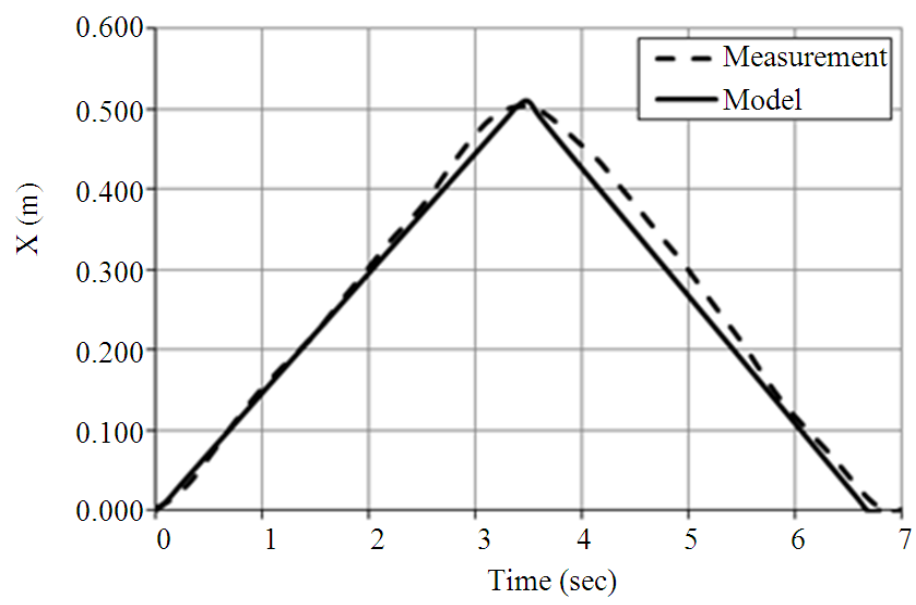

Fig. 5. Hydraulic cylinder rod velocity

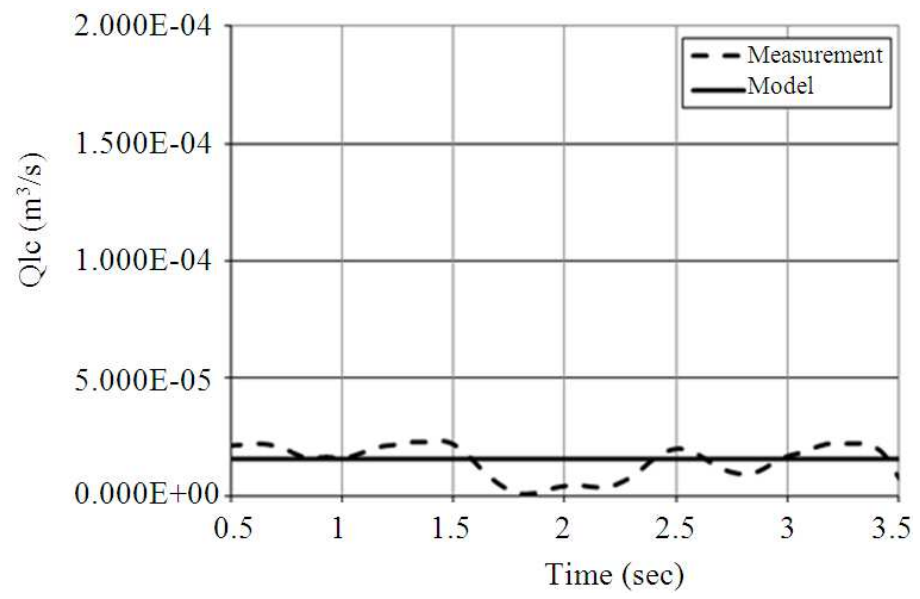

Fig. 6. Hydraulic cylinder internal leakage

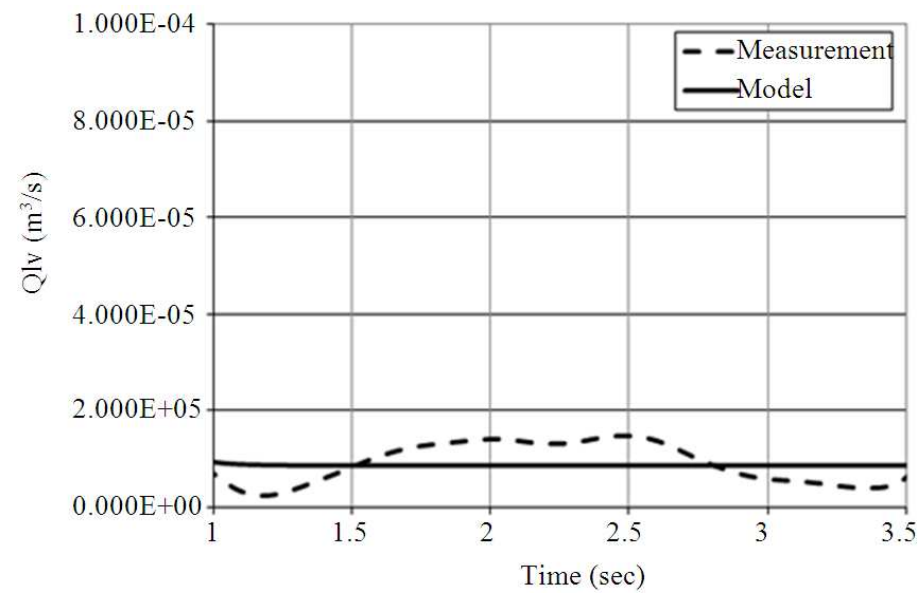

Fig. 7. 4/2 way valve internal leakage 
P. Athanasatos et al. / American Journal of Applied Sciences 10 (12): 1648-1659, 2013

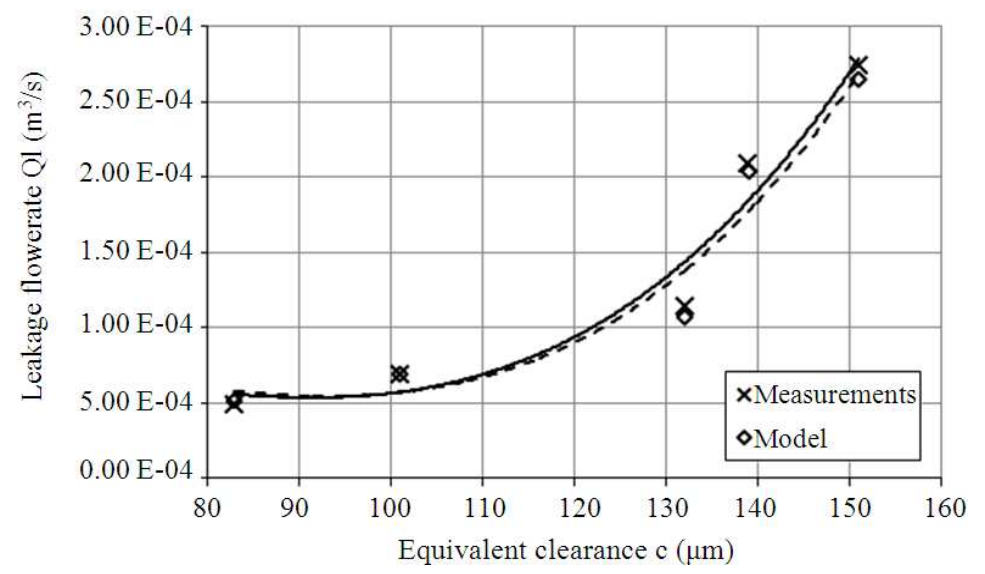

Fig. 8. Comparison of equivalent leakage flow rate between experimental and model data for $\mathrm{F}_{\text {load }}=6.3 \mathrm{kN}$

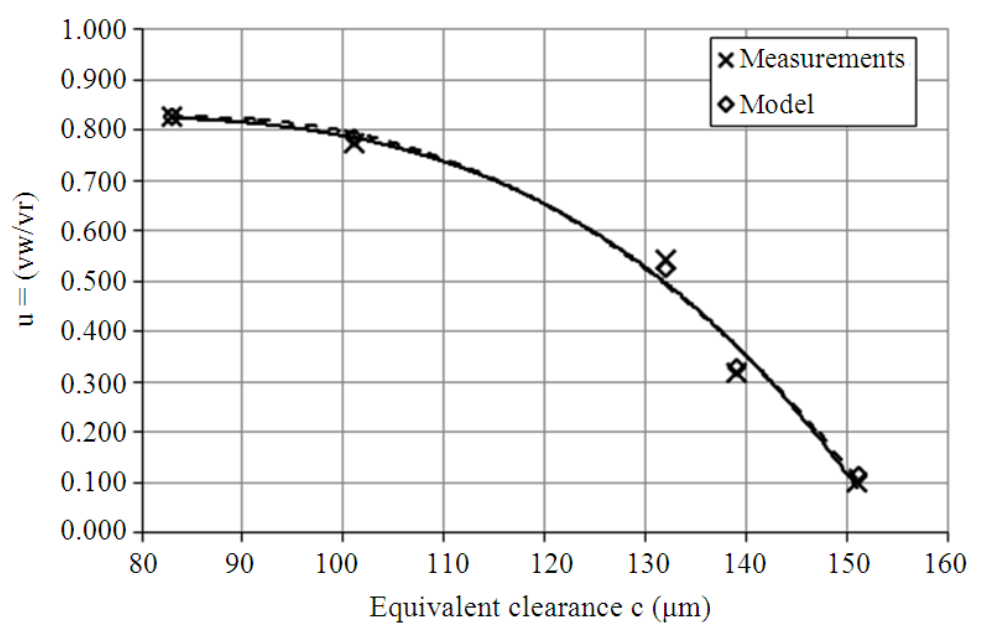

Fig. 9. Comparison of working to return piston velocity ratio between experimental and model data for $F_{\text {load }}=6.3 \mathrm{kN}$

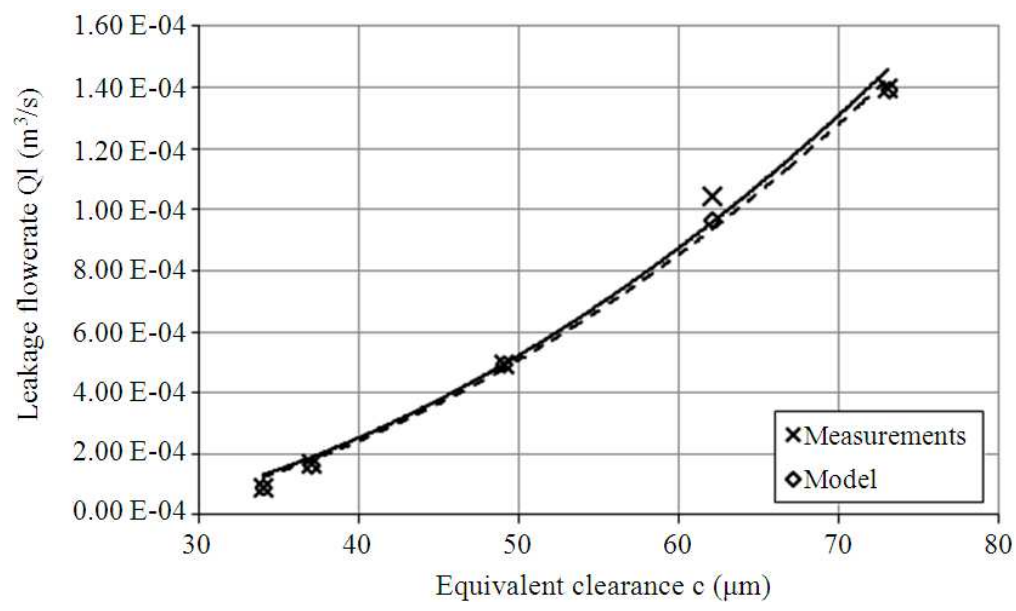

Fig. 10. Comparison of equivalent leakage flow rate between experimental and model data for $F_{\text {load }}=6.3 \mathrm{kN}$ 


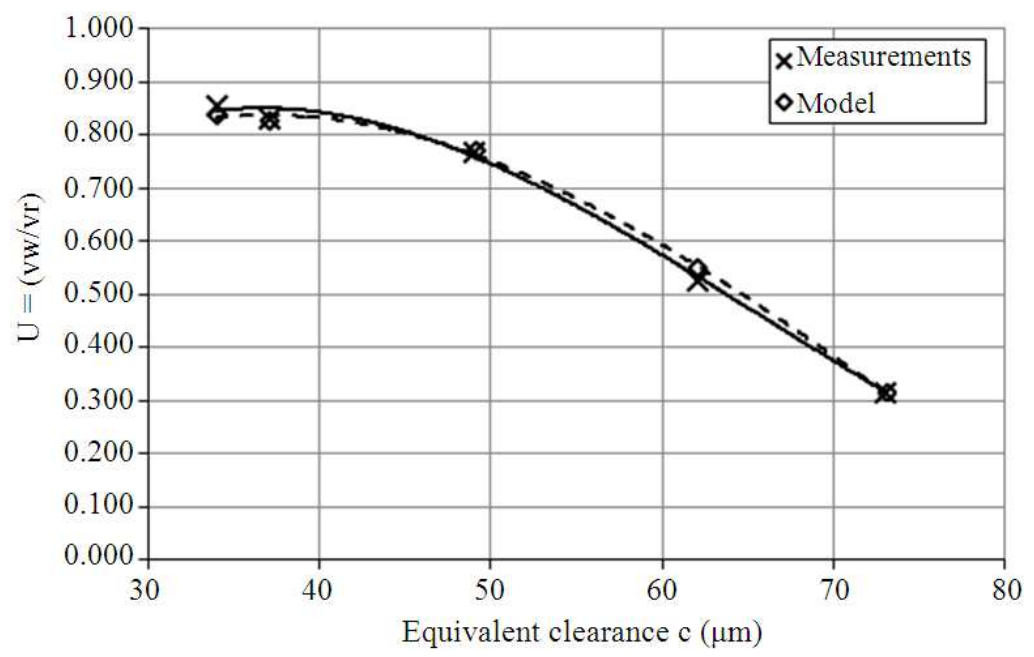

Fig. 11. Comparison of working to return piston velocity ratio between experimental and model data for $F_{\text {load }}=6.3 \mathrm{kN}$

\subsection{Results for Internal Leakage in the $4 / 2$ Way Direction Control Valve}

Again, the values of equivalent clearances for the $4 / 2$ way valve calculated before were used in the model and the results were compared with the ones of the actual system. In Fig. 10 and 11, the comparison of equivalent internal leakage values and the piston velocity ratio values of the model and the actual system for an equivalent load of $6.3 \mathrm{kN}$ are shown. The correlation coefficients of experimental and model data are again very high $(r=0.998)$, with the regression curves for both the experimental (continuous line) and the model data (dashed line) having the form of a 3rd degree polynomial equation.

\section{CONCLUSION}

The Bond Graph method, albeit comparatively new, is rather popular in the modeling of physical systems but its applications in high pressure hydraulic systems remain somewhat limited. A comparison of the Bond Graph method with object oriented modeling is met in the literature, where it is found that both methods can be equally reliable, if they are used in appropriate applications and effectively implemented. In this study, a model of an actual high pressure hydraulic system has been developed, in order to be used for proactive fault finding. The main components of the hydraulic system were modeled separately and then they were combined to form the model of the entire system. The present model is focused on the effects of the internal leakage of the hydraulic cylinder and the 4/2 way direction control valve on system's operation. The results of the model were compared to the results provided by an actual hydraulic system, modified in order to simulate various loads and degrees of internal leakage in the hydraulic cylinder and the $4 / 2$ way valve. Comparisons were made both during normal operation of the system and during simulation of increased internal leakage in the cylinder and the valve. In all cases, the results of the model correlate very well to the data provided by the actual system both in shape and in minima and maxima of the curves. The equivalent internal leakage in the hydraulic cylinder and the $4 / 2$ way valve is a function of the equivalent internal clearance that has the form of a $3 \mathrm{rd}$ degree polynomial equation, as it is evident by the regression curves in both the experimental and the modeling data. Additionally, the ratio of the average velocity of the cylinder's piston in the working phase to the average velocity in the return phase is also a function of the equivalent internal clearance of the hydraulic cylinder and the $4 / 2$ way valve in the form of a $3 \mathrm{rd}$ degree polynomial equation. This also means that this ratio can be used as an index for the assessment of the internal clearance of the cylinder and the valve, given that it is fairly easy to calculate, unlike the more complex procedure and needed instrumentation required to measure the internal leakage. This could prove useful in real life applications of high pressure hydraulic systems where it is evident that there is a problem, but the source of it cannot be easily traced. This is very important in industrial production systems where unpredictable shutdowns of the hydraulic machinery have a 
considerable negative economic impact on cost. In situations like this the application of modeling techniques could also help the troubleshooting procedure even further, by allowing the simulation of "fault scenarios" in various components of the system, in order to locate the source of the problem. However, this application should be prepared by highly qualified personnel.

\section{REFERENCES}

Athanasatos, P. and T. Costopoulos, 2011. Proactive fault finding in a 4/3-way direction control valve of a high pressure hydraulic system using the bond graph method with digital simulation. Mechanism Mach. Theory, 50: 64-89. DOI: 10.1016/j.mechmachtheory.2011.11.018

Barnard, B.W. and P. Dransfield, 1977. Predicting response of a proposed hydraulic control system using bond graphs. J. Dyn. Syst. Measur. Control, 99: 1-8. DOI: $10.1115 / 1.3427068$

Borutzky, W., 2002. Bond graphs and object-oriented modeling-a comparison. J. Syst. Control Eng., 216: 21-33. DOI: 10.1243/0959651021541408

Costopoulos, T., 2009. Hydraulic and Pneumatic Systems. 1st Edn., Athens Symeon Publishing Company.

Dransfield, P., 1981. Hydraulic and Pneumatic SystemsDesign and Analysis of their Dynamics. 1st Edn., Springer-Verlag, Berlin, ISBN-10: 0387108904, pp: 227.

Gawthorp, P.J., D.J. Wagg and S.A. Neild, 2009. Bond graph based control and substructuring. Simulat. Model. Pract. Theory, 17: 211-227. DOI: 10.1016/j.simpat.2007.10.005

Kaliafetis, P. and T. Costopoulos, 1995. Modeling and simulation of an axial piston variable displacement pump with pressure control. Mechanism Mach. Theory, 30: 599-612 DOI: 10.1016/0094114X(94)00057-R

Krishnaswamy, K. and P.W. Li, 2006. Bond graph based approach to passive teleoperation of a hydraulic backhoe. J. Dyn. Syst. Measur. Control, 128: 176185. DOI: $10.1115 / 1.2168475$
Li, P.Y. and R.F. Ngwempo, 2005. Power scaling bond graph approach to the passification of mechatronic systems-with application to electrohydraulic valves. J. Dyn. Syst. Measur. Control, 127: 633-641. DOI: 10.1115/1.2101848

Margolis, D. and T. Shim, 2005. Bond graph modelling for non-linear hydro-mechanical systems. J. Multi-body Dyn., 219: 371-382. DOI: 10.1243/146441905X34117

Meritt, H.E., 1991. Hydraulic Control Systems. 1st Edn., John Wiley and Sons, Inc., ISBN-10: 0471596175, pp: 368.

Noorbehesht, N. and P. Ghaseminejad, 2013. Numerical simulation of the transient flow in natural gas transmission lines using a computational fluid dynamics method. Am. J. Applied Sci., 10: 24-34. DOI: 10.3844/ajassp.2013.24.34

Rabie, G.M., 2009. Fluid Power Engineering. 1st Edn., McGraw-Hill, New York, ISBN-10: 0071626069, pp: 448.

Siam, A.Z., K. Alkhameteeb and S. Al-Waqqad, 2012. The role of information systems in implementing total quality management. Am. J. Applied Sci., 9: 666-672. DOI: 10.3844/ajassp.2012.666.672

Skarmea, M., 2003. Condition monitoring techniques for fluid power systems and components. M.Sc. Thesis, Mechanical Engineering Department, Bath University.

Valarmathi, R. and A. Chilambuchelvan, 2012. Power quality analysis in $6 \mathrm{MW}$ wind turbine using static synchronous compensator. Am. J. Applied Sci., 9: 111-116 DOI: 10.3844 /ajassp.2012.111.116

Zotos, I. and T. Costopoulos, 2008. A study on the increase of numerical stability and accuracy of the transfer matrix method. J. Math. Stat., 4: 208-212. DOI: $10.3844 /$ jmssp.2008.208.212

Zotos, I. and T. Costopoulos, 2012. On the use of rolling element bearings models in precision maintenance. Am. J. Eng. Applied Sci. DOI: 10.3844/ajassp.2012.666.672 